\title{
As Diretrizes Curriculares Nacionais para os Cursos de Licenciatura em Ciências da Natureza e o Enfoque CTS
}

\section{The National Curricular Guidelines for Science Courses in Nature Sciences and the CTS Approach}

\author{
$\begin{aligned} \text { Jucelino Cortez } & { }^{(0)} \text { Brasil } \\ \text { José Claudio Del Pino } & { }^{(0)} \text { Brasil }\end{aligned}$
}

Este artigo relata a síntese de uma pesquisa qualitativa, aplicada, com procedimento bibliográfico, feita junto as Diretrizes Curriculares Nacionais para os cursos de Licenciatura em Física, em Ciências Biológicas e em Química de 2001, e na Resolução $n^{\circ} 2$ de julho de 2015. O objetivo do trabalho está voltado para a busca de relação entre as orientações destes documentos oficiais e os princípios do enfoque CTS. A partir do estudo, apontamos os principais pontos que nos confirmam a existência desta relação, considerando que estas normativas e a relação aqui evidenciada podem contribuir, junto com a atuação dos educadores, para a melhoria do ensino das Ciências da Natureza, tanto em nível básico como no superior.

Palavras-chave: Enfoque CTS; Ensino de Ciências; Diretrizes; Licenciaturas.

This article presents the synthesis of a qualitative, applied research, with bibliographic procedure, carried out according to the National Curricular Guidelines for the undergraduate courses in Physics, Biological Sciences and Chemistry of 2001, and Resolution $\mathrm{n}^{\circ} 2$ of July 2015 The aim of this work is focused on the search for a possible relationship between the guidelines of the official documents and the principles of the CTS approach. From this study, we pointed out the main points that confirm the existence of this relationship, considering that these normatives and a relationship here evidenced can contribute, together with the educators' actions, to improve the teaching of the Nature Sciences, both in basic and in higher educational levels.

Keywords: CTS Approach; Science Teaching; Guidelines; Undergraduate Courses.

\section{Introdução}

O ensino das Ciências desenvolvido nas escolas do mundo todo vem sofrendo sensíveis alterações há mais de trinta anos. Estas, ocorrendo de forma lenta e constante, têm provocado questionamentos acerca do perfil do educando que queremos formar.

O trabalho de Aikenhead (1985), por exemplo, cita que no primeiro Simpósio Internacional sobre Tendências Mundiais em Educação em Ciências em 1980, realizado 
no Canadá, já se argumentava que em todo e qualquer ensino de ciências, deve-se desenvolver nos educandos a capacidade de tomada de decisão e a responsabilidade social (Aikenhead, 1985).

No Brasil, o contexto acerca das necessidades de melhorarmos o ensino das Ciências não é diferente. Por exemplo, o site UOL Educação, ao mencionar o Relatório Nacional PISA 2012, cita que nossa educação está desenvolvendo um perfil de educando que só é capaz de aplicar o que sabe apenas a poucas situações de seu cotidiano (Tokarnia, 2016).

Segundo Rosa e Rosa (2012), as mudanças no ensino de Ciências vêm acontecendo, mas não estão alcançando os objetivos pretendidos.

Observou-se que esse ainda era praticado, na sua grande maioria, por professores que desconheciam tais relações, mantendo-se arraigados aos processos de ensino tradicional, voltados apenas para a informação, sem qualquer vínculo com as concepções modernas de educação. Muitas foram as propostas de reformulação do ensino de Ciências, sempre visando as necessidades de melhoria da sociedade e ao progresso da tecnologia (Rosa, \& Rosa, 2012, p. 9).

Cachapuz, Paixão, Lopes e Guerra (2008) defendem a necessidade de um olhar mais crítico e social para o ensino das Ciências e enfatizam que uma das linhas de pesquisa que tem merecido bastante atenção nos últimos tempos é a dos estudos de Ciência-Tecnologia-Sociedade (CTS). Segundo estes autores:

A relevância social e cultural da ciência numa sociedade sustentada na ciência e na tecnologia converge, necessariamente, para uma resultante "sócio-cívica" (Hlebowitsh \& Hudson, 1991), ou "responsabilidade social" como lhe chama Ramsey (1993), e são estes vetores que têm vindo a orientar de modo mais ou menos explícito a grande maioria das reformas educativas desde os anos 80 e 90 do século XX (Cachapuz, Paixão, Lopes, \& Guerra, 2008, p.2).

O governo federal também apresenta sugestões na busca de melhorias da nossa educação, tanto no nível básico quanto no nível superior. Desde a publicação da Lei de Diretrizes e Bases da Educação Nacional (LDB) em 1996, o Ministério da Educação (MEC) propõe uma reforma de ensino em todos os níveis de escolaridade, elaborando e oferecendo como norteamento para professores e instituições de ensino, orientações como os Parâmetros Curriculares Nacionais (PCN) de 1997, as Diretrizes Curriculares Nacionais (DCN) para as Licenciaturas de 2001 e para a Educação Básica em 2013. Estes documentos, junto com outros de menor relevância, visam um processo educativo contextualizado, interdisciplinar, focado em desenvolver habilidades e competências, no lugar da simples assimilação de conteúdos.

A partir destes documentos o governo federal orienta, no chamado Plano de Desenvolvimento da Educação, que uma educação sistêmica deve valorizar e articular conjuntamente a todos os níveis e modalidades educacionais, as ações que organizam o sistema de ensino. Esta proposta possibilita um ciclo educacional integralizado com suas diferentes etapas, promovendo articulações entre educação básica e educação superior 
(Parecer CNE/CEB n 7/2010, 2013). Conforme o plano:

Visão sistêmica implica, portanto, reconhecer as conexões intrínsecas entre Educação Básica e Educação Superior; entre formação humana, científica, cultural e profissionalização e, a partir dessas conexões, implementar políticas de educação que se reforcem reciprocamente (Parecer CNE/CEB no 7/2010, 2013, p. 149).

Neste contexto, as universidades, e, neste caso, os cursos de licenciatura das áreas de Ciências da Natureza, ocupam papel de grande importância, pois segundo as diretrizes: "Como produtora de saber e formadora de intelectuais, docentes, técnicos e tecnólogos, a universidade contribui para a construção contínua do mundo e sua configuração presente" (Parecer CNE/CES nº 1.303, 2001, p. 1).

Com esta perspectiva, fizemos uma pesquisa bibliográfica qualitativa, com a intenção de analisarmos as DCN de 2001 dos cursos de licenciatura em Física, em Química e em Ciências Biológicas, integrantes da grande área das Ciências da Natureza, e as orientações da Resolução $n^{\circ} 2$, de $1^{\circ}$ de julho de 2015, buscando indicações que possam ser relacionadas com o uso da abordagem CTS. Utilizamos como norteamento os principais tópicos da abordagem CTS nos trabalhos de Aikenhead e Salomon (1994), Santos e Mortimer (2002), Auler (2002), Cerezo (1998) e Zimam (1994).

O objetivo principal desta análise é identificar pontos nas diretrizes dos cursos de licenciatura das Ciências da Natureza, que estão consoantes com o enfoque CTS, para podermos ter uma ideia do quanto estas orientações sugerem, junto aos cursos de graduação, situações que despertem nos acadêmicos, discussões acerca do uso da abordagem CTS no ensino básico. A nosso ver, isto é importante, pois a partir daí os educandos poderiam vir a desenvolver este enfoque quando tornarem-se professores.

Justificamos esta pesquisa na necessidade de melhorarmos o ensino de Ciências na educação básica e acreditamos que as DCN das licenciaturas influenciam de maneira direta na formação dos futuros professores do ensino fundamental e médio, considerando que suas linhas balizam os Planos Pedagógicos dos Cursos (PPC) que preparam estes educandos para serem os próximos educadores.

O artigo está organizado da seguinte maneira:De início, faz-se um resgate histórico do movimento e dos currículos CTS, procurando destacar as principais características deste enfoque que serve de referencial teórico para este estudo. Na sequência, procuramos realizar a análise das diretrizes, pontuando, por fim, os resultados desta pesquisa, a partir dos quais propomos considerações que julgamos pertinentes.

\section{Referencial Teórico - O Enfoque CTS}

Para entendermos as origens deste enfoque, começamos observando que as sociedades desenvolvidas começaram a receber uma influência mais forte da ciência e da tecnologia após a revolução industrial, chegando ao ponto em que estes grupos passaram, a partir da segunda metade do século XX, a acreditar numa relação de qualidade de vida dependente da tecnologia. Esta relação estava baseada no princípio da linearidade. Este princípio teoriza que, quanto mais desenvolvemos pesquisa científica, 
maior o número de projetos de pesquisa aplicada e, quanto mais pesquisa aplicada, mais tecnologia, resultando então em aumento do bem estar dos indivíduos e maior qualidade de vida da sociedade como um todo (Miranda, 2013).

Esta concepção, fundamentada na visão positivista, consolidada no século XIX na voz de Augusto Comte, considera que a única base verdadeira do conhecimento é a ciência e que também esta contribui para a solução de todos os problemas da humanidade.

Outra característica marcante do positivismo baseia-se na ideia de que a ciência é progressiva e cumulativa na aquisição de conhecimentos científicos e, portanto, distinta e superior a qualquer outro tipo de conhecimento (Ramos, Neves, \& Corazza, 2011, p. 87).

Segundo Sarewitz, esta perspectiva cria o chamado "mito do benefício infinito", pois passa a ideia de que esse modelo linear não teria limites nem restrições e este mito estaria associado a outros quatro mitos: $\mathrm{O}$ mito da pesquisa sem restrições, que afirma que a ciência por ser neutra, poderia beneficiar a sociedade de um modo ou de outro, independente do tipo de pesquisa. Outro mito é o da prestação de contas, que considera como maior forma de controle nas pesquisas, os próprios mecanismos de controle propostos por quem pesquisa, bem como a responsabilidade ética de seus pesquisadores. $\mathrm{O}$ autoritarismo constitui o terceiro mito, ao afirmar que o conhecimento científico fornece base objetiva para resolução de disputas políticas. O último mito é o da fronteira sem fim e afirma que os conhecimentos gerados são autônomos em suas consequências morais e práticas para a sociedade (Sarewitz, 1996, citado por Miranda, 2013).

Para José A. L. Cerezo: “A concepção clássica da relação entre ciência, tecnologia e sociedade ainda muito presente em vários campos da academia e da mídia de massa, é uma concepção essencialista e triunfalista" (Cerezo, 1998, p. 1) e, resumindo esta concepção, o autor ainda afirma que a visão positivista pode ser expressa na equação:

$$
+ \text { Ciência }=+ \text { tecnologia }=+ \text { riqueza }=+ \text { bem-estar social }
$$

Entretanto, Salomon, Sagasti e Sachs-Jeantet destacam que, junto com as melhorias na qualidade de vida das pessoas, o crescimento tecnológico trouxe, para as nações em desenvolvimento e até para as industrializadas, sérios problemas como desemprego, bolsões de pobreza e desigualdade social em questões referentes à educação e saúde (Salomon, Sagasti, \& Sachs-Jeantet, 1993).

Ainda, segundo estes autores:

É a partir deste angulo que as relações entre ciência, tecnologia e sociedade nos países em desenvolvimento devem ser entendidas. Além de certo nível de recursos, a acumulação de capital nunca é por si só garantia de crescimento. Ao contrário, a organização da sociedade - a qual, por sua vez, determina a organização da produção - é o fator principal que torna possível a um país criar e explorar seus recursos científicos e tecnológicos. Esses fatores definem a extensão em que a ciência e a tecnologia podem operar para iniciar e estimular o processo de desenvolvimento, e não vice-versa (Salomon, Sagasti, \& Sachs-Jeantet, 1993, p. 5). 
O uso das tecnologias a serviço de fins militares e as consequências diretas e indiretas que estes avanços provocaram, contracenaram com uma visão salvacionista da ciência, causando abalo na convicção do modelo linear de desenvolvimento científico e tecnológico. Ficou evidente que existe sim o mito do benefício infinito, mas surgiu uma dúvida na sociedade: Esse benefício beneficia quem?

É neste contexto que o movimento CTS surge, sem ter uma data de fundação nem um grupo gerador com uma pauta de resoluções definidas. Podemos afirmar que o movimento se consolida aos poucos, na América do Norte, com uma forte veia ativista, através de boletins informativos, revistas e livros polêmicos, alguns protestos; e na Europa com um cunho mais acadêmico, visando uma compreensão teórica e as possíveis estratégias para ações acadêmicas. Ainda referindo-se às origens do movimento, Décio Auler afirma que:

Com o passar do tempo, em sua análise, foi diminuindo o compromisso militante, migrando para o ethos acadêmico, ocorrendo, com os estudos CTS, o desenvolvimento de níveis mais complexos e sofisticados tanto de teorização quanto de métodos de indagação e análise. A militância deu lugar à formação de especialistas (Auler, 2002, p. 28).

Além da origem norte-americana e da europeia, merece destaque também a vertente Latino Americana, com um enfoque mais voltado para as políticas públicas relacionadas com a ciência e a tecnologia. Esta veia ficou conhecida como Pensamento Latino Americano em CTS (PLACTS) (Vaccarezza, 1998).

Estas diferentes origens, segundo Cerezo (1998), servem somente como resgate histórico, sendo que, atualmente, independente da tradição, podemos vislumbrar três campos de ação: na pesquisa acadêmica, nas políticas públicas e na educação. Para este teórico, as ações voltadas para a educação abarcam programas filosóficos, sociológicos e históricos, enfatizando a dimensão social da ciência e da tecnologia, objetivando a oposição à concepção de ciência pura e neutra, a crítica à definição de tecnologia como sendo aplicação de ciência e a discussão acerca da participação pública na tomada de decisão.

No campo da educação, segundo John Ziman (1980), o movimento dá origem ao enfoque CTS, tendo como principais características, a valorização do contexto social e político, a formação cidadã do educando e a oposição à concepção positivista que orientava a escola a formar um cientista. Os currículos que valorizam a abordagem CTS, devido a estas características, segundo este autor, abarcam sete categorias que, juntas, se complementam, dando corpo à abordagem CTS no ensino das Ciências. Estas categorias são o enfoque na relevância, promovendo a compreensão da ciência por meio de suas aplicações, valorizando a ciência na vida cotidiana; o enfoque vocacional, apresentando a ciência e a tecnologia com intuito de formar um profissional no futuro; o enfoque interdisciplinar, apresentando a ciência de forma não fragmentada, com uma visão integrada de conhecimento; o enfoque histórico, inserindo a ciência e a tecnologia no contexto de mudanças histórico-sociais; o enfoque filosófico, propondo discussões 
acerca da natureza do conhecimento científico; o enfoque sociológico, abordando ciência e tecnologia a partir das instituições sociais e discutindo como as universidades e indústrias se relacionam com a sociedade; e o enfoque na problematização, apresentando e discutindo questões sociais, bem como causas e consequências envolvidas na relação CTS (Ziman, 1994).

Outro teórico precursor nos estudos da abordagem CTS é Glen Aikenhead. Para este autor os currículos CTS se caracterizam por valorizar a contextualização, visando abordar conteúdos de Ciências de forma conectada e integrada com o cotidiano dos alunos; a tomada de decisões, procurando desenvolver a responsabilidade social do educando; o currículo orientado no aluno, considerando-o como cidadão antes de um futuro cientista; e, por fim, a formação crítica para o exercício da cidadania (Aikenhead, 1994).

No Brasil, vários pesquisadores discorrem sobre o tema, merecendo destaque os estudos de Auler e Bazzo (2001), Auler (2002), Linsingen (2002), Santos e Mortimer (2002), Pinheiro (2005), Miranda (2013), Strieder (2012), entre outros. Segundo estas pesquisas, os currículos CTS devem propor: a ciência como atividade humana, relacionada, portanto, com questões sociais; orientações para uma sociedade que pode tomar decisões frente aos problemas sociais relacionados com a tecnologia e com a ciência; a formação de um aluno crítico que compreenda a base científica das inovações tecnológicas; o envolvimento de um professor comprometido com as inter-relações complexas entre ciência e tecnologia e o desenvolvimento intelectual do aluno. Ainda, segundo Pinheiro (2005), o enfoque CTS, no contexto educacional objetiva: questionar as formas herdadas de estudar a natureza; questionar a distinção convencional entre conhecimento teórico e prático, assim como sua distribuição social; combater a segmentação do conhecimento; e promover de forma crítica a democratização do conhecimento.

Visando orientar os professores no uso da abordagem, Aikenhead e Salomon (1994) afirmam que devemos priorizar conceitos científicos e tecnológicos relacionandoos com perspectivas culturais e sociais, buscando soluções de problemas e tomada de decisões. Para compormos as estratégias de ensino, os autores sugerem o uso de um problema social como meio de introduzir um tema, analisando, em seguida, as tecnologias envolvidas e os impactos que tais tecnologias promovem junto à sociedade.

Ainda, recorrendo a Santos e Mortimer, deve-se destacar que:

O objetivo central da educação de CTS no ensino médio é desenvolver a alfabetização científica e tecnológica dos cidadãos, auxiliando o aluno a construir conhecimentos, habilidades e valores necessários para tomar decisões responsáveis sobre questões de ciência e tecnologia na sociedade e atuar na solução de tais questões (Santos, \& Mortimer 2002, p. 4).

Diante destas características que o currículo CTS deve possuir, percebe-se seu caráter multidisciplinar, com observância nos contextos social e cultural, com as propostas curriculares passando a propor que educandos devem entender o caráter 
provisório e incerto da ciência, tendo capacidade de analisar e de ter posição na resolução de problemas. Segundo estes autores, quando buscamos este objetivo, os alunos desenvolvem comunicação oral e escrita, pensamento lógico, responsabilidade social e principalmente, o interesse pelo tema abordado (Santos, \& Mortimer, 2002).

\section{Referenciais Metodológicos}

Ao considerarmos, segundo o referencial teórico escolhido, a abordagem CTS como uma excelente prática na melhoria do ensino das Ciências, sentimos a necessidade de verificar como estes pressupostos são concomitantes com as orientações governamentais que tratam do ensino superior formador dos futuros profissionais da educação. Por isso, voltamos nosso olhar para as Diretrizes Curriculares Nacionais para as Licenciaturas.

Escolhemos realizar uma pesquisa de natureza aplicada, com abordagem qualitativa, por considerar, segundo Gerhardt e Silveira (2009), que estamos buscando conhecimentos para aplicações práticas, sem pretensões de quantificações e sim, estamos interessados em compreender e explicar a dinâmica das relações considerando motivos, valores e atitudes que não podem ser operacionalizados com variáveis.

Neste sentido, optamos neste estudo, quanto aos objetivos, por realizar uma pesquisa exploratória com procedimento bibliográfico, considerando que estamos buscando maior familiaridade com a situação (Fonseca, 2002). Visamos atingir tal intuito, nos direcionamos às referências teóricas oferecidas pelo governo federal, através do Ministério da Educação, buscando identificar, em seus textos, os pressupostos teóricos do enfoque CTS.

\section{Análise das Diretrizes Curriculares Nacionais para as Licenciaturas}

As DCN para os cursos de Licenciatura em Física, Ciências Biológicas e Química, de 2001, são os documentos oficiais que têm norteado os PPC destes cursos e estão organizadas, por linhas gerais, seguindo uma mesma sequência. Esta começa apresentando o que se deseja referente ao perfil dos formandos, seguindo por uma orientação com as competências e habilidades que devem ser desenvolvidas nos cursos. Para atingir tais pressupostos, o documento segue orientando sobre a estrutura dos cursos e seus conteúdos curriculares, deixando, por fim, uma sugestão referente às distribuições destes conteúdos e às estruturas modulares comuns e complementares que devem ser oferecidas.

Em cada um destes itens citados nas diretrizes, procuramos identificar as relações propostas, comparando também esta afinidade com cada curso especificado no estudo. 


\section{Perfil dos Formandos}

As diretrizes dos cursos de Física diferenciam perfis dos formandos, classificando-os como pesquisador, educador, tecnólogo ou interdisciplinar. Entretanto, tal documento destaca que, independente do perfil, o profissional deve: "[...] ser capaz de abordar e tratar problemas novos e tradicionais e deve estar sempre preocupado em buscar novas formas do saber e do fazer científico ou tecnológico" (Parecer CNE/CES nº 1.304, 2001, p. 3).

Estas novas formas de saber e de fazer, segundo Ziman (1980), alteram o modelo convencional de abordar ciência, pois tradicionalmente, considera-se a ciência como produção exclusiva da comunidade científica. Para este autor, a perspectiva CTS é mais ampla que esta visão convencional ao considerar que a ciência não é neutra, não está como modeladora da sociedade, nem está linearmente definindo a verdade.

Por outro lado, as diretrizes para os cursos de Ciências Biológicas, de forma muito direta, elencam sete itens que devem qualificar o formando. Destes itens, destacamos um que orienta para a ética e a cidadania e outro que defende uma atuação multi e interdisciplinar.

Para este egresso, o documento aborda a necessidade de conhecimento específico da área, mas destaca a responsabilidade que o profissional deve ter com os resultados de sua atuação, sendo esta pautada por critérios humanísticos, compromisso com a cidadania e com o meio ambiente, orientando a formação crítica, ética e cidadã do formando, citando, inclusive, valores como "espírito de solidariedade" (Parecer CNE/ CES no 1.301, 2001).

No trabalho de Aikenhead (2003), também observamos referência à cidadania. Para este teórico, o enfoque CTS no ensino de Ciências orienta para uma formação científica que promova a cidadania, considerando que as práticas do ensino devem priorizar a formação do cidadão crítico e ético.

Ainda analisando a atuação multidisciplinar no perfil do egresso, Santos e Mortimer, (2002) defendem que os conceitos científicos devem sempre ser desenvolvidos numa perspectiva relacional, de maneira a evidenciar as diferentes dimensões do conhecimento estudado, sobretudo as interações entre ciência, tecnologia e sociedade.

Para os cursos de Química, as DCN começam enfatizando, nas palavras do relator Francisco César de Sá Barreto, um olhar ao novo paradigma educacional, orientando que os currículos sejam eficazes e envolventes.

Os currículos vigentes estão transbordando de conteúdos informativos em flagrante prejuízo dos formativos, fazendo com que o estudante saia dos cursos de graduação com "conhecimentos" já desatualizados e não suficientes para uma ação interativa e responsável na sociedade, seja como profissional, seja como cidadão [...] Diante dessa constatação, advoga-se a necessidade de criar um novo modelo de curso superior, que privilegie o papel e a importância do estudante no processo da aprendizagem, em que o papel do professor, de "ensinar coisas e soluções", passe a ser "ensinar o estudante a aprender coisas e soluções (Parecer CNE/CES no 1.303, 2001, p. 1). 
O relator sugere ainda que o ensino não seja mais seccionado e departamentalizado e que as instituições de ensino reconheçam seu verdadeiro papel social.

Uma das formas de não fragmentar conhecimentos pode estar na diversidade de ações promovidas junto aos educandos, afirmam Santos e Mortimer (2002). Para estes autores, o ensino de Ciências deve envolver estudos de caso, visitas técnicas, seminários e debates envolvendo situações reais do contexto em que a escola está inserida, contribuindo para que a educação tenha de fato o reconhecimento de seu papel social.

\section{Competências e Habilidades}

Para os cursos de Física, existe uma preocupação destacada nestas DCN com as novas demandas que estão emergindo nos últimos anos em relação às transformações que vem ocorrendo na sociedade. Mesmo abordando que as perspectivas tradicionais de atuação da prática pedagógica continuam em voga, o documento alerta para o desafio de propor novas ações com caráter dinâmico e interessante.

O documento considera algumas competências que são essenciais para os formandos. Dentre elas, destacamos a necessidade de descrever e explicar o funcionamento de equipamentos tecnológicos bem como desenvolver a ética de atuação profissional e a responsabilidade social, compreendendo ciência como conhecimento histórico, desenvolvido em diferentes contextos sócio-políticos, culturais e econômicos (Parecer CNE/CES nº 1.304, 2001).

Quanto às habilidades, o documento apresenta orientações que são consideradas de âmbito generalizado, merecendo destaque em nosso estudo as que orientam para a capacidade do licenciado em Física em: "Reconhecer as relações do desenvolvimento da Física com outras áreas do saber, tecnologias e instâncias sociais, especialmente contemporâneas" (Parecer CNE/CES no 1.304, 2001, p. 4).

Em relação às citações descritas, Ziman (1994), afirma que o desenvolvimento das sociedades e o processo evolutivo da ciência todas estão intimamente ligados, sendo que o enfoque histórico e o sociológico permitem promover, junto aos educandos, condições de reconhecer a ciência e a tecnologia como instituições sociais que repercutem diretamente na sociedade.

Nas DCN para os cursos de Ciências Biológicas, além da orientação para o pleno desenvolvimento dos conhecimentos em sua área, valoriza-se em muitos itens, de forma muito enfática, a responsabilidade social e ambiental, os princípios éticos, a formação do cidadão e a capacidade de utilizar seus conhecimentos para alterar o contexto social.

Este documento também valoriza a relação entre a ciência, a tecnologia e a sociedade de forma específica e considera a necessidade de este profissional comprometer-se com o desenvolvimento tecnológico no mundo, bem como entender o processo histórico de produção deste.

Reforçando esta orientação, Aikenhead (1994) afirma que é preciso que os educandos, além de conhecer e participar do desenvolvimento dos processos científicos e tecnológicos, participem de discussões e estudos acerca da importância desta ciência 
para a sociedade, abordando-a de forma não neutra e nem tão pouco salvacionista.

Esta visão crítica da ciência também aparece nas competências e as habilidades para os cursos de Química que, distinguindo licenciados de bacharéis, orienta os primeiros, para o desenvolvimento de uma capacidade crítica em analisar seus próprios conhecimentos, bem como a necessidade de refletir sobre o comportamento ético compatível com sua atuação junto à sociedade (Parecer CNE/CES no 1.303, 2001). Ainda em relação à formação pessoal, este documento valoriza o desenvolvimento da visão crítica em relação ao papel social da ciência e seu processo histórico social de construção.

Estas orientações ainda elencam, com relação ao ensino de Química, uma forte referência à visão crítica dos aspectos sociais, tecnológicos, ambientais, políticos e éticos relacionados às aplicações da Química na sociedade.

Com relação à profissão, merece destaque, como competências e habilidades do licenciado em química, os itens que citam a importância social da profissão e o compromisso de preparar os alunos para o exercício consciente da cidadania.

Conforme orienta Aikenhead (1994), a educação deve estar atenta à necessidade de criar condições de oferecer uma formação crítica para o exercício da cidadania e, conforme estas diretrizes, ainda continuamos com a necessidade de alterar o ensino tradicional que se caracteriza por estar voltado para conteúdos e não para o desenvolvimento de competências.

Para Santos e Mortimer (2002), cada vez mais a ciência e a tecnologia tem exercido interferência na sociedade, mas também cada vez mais, essas são motivos de discussões acerca do seu uso, dos seus efeitos e suas aplicações. Estas discussões no contexto dos estudos sobre ciência vêm motivando discussões acerca de uma educação com currículos mais voltados para o contexto em que a ciência está inserida, exigindo dos atores participantes, novas habilidades para competências mais complexas.

\section{Estrutura dos Cursos}

Para desenvolver as competências e as habilidades propostas neste documento, os cursos devem ser estruturados em dois núcleos curriculares distintos. O núcleo comum, com as disciplinas gerais e o núcleo dos módulos sequenciais, característicos de cada modalidade.

Nas orientações para a estrutura dos cursos de Física, encontramos uma tênue relação com o enfoque CTS:

Os conteúdos desses módulos especializados interdisciplinares devem ser elaborados por cada IES juntando os esforços dos colegiados dos diversos cursos envolvidos (Física, outras áreas científicas, Engenharia, Comunicação, etc.) seguindo interesses específicos e regionais de cada instituição (Parecer CNE/CES n 1.304, 2001, p. 6).

Para os cursos de Ciências Biológicas, o documento enfatiza que a estrutura do curso deve: "Garantir um ensino problematizado e contextualizado, assegurando a indissociabilidade entre ensino, pesquisa e extensão" (Parecer CNE/CES nº 1.301, 2001, 
p. 4).

A problematização de situações e temas constitui uma excelente forma de garantir um ensino voltado para o contexto em que as instituições de ensino superior estão incluídas, oferecendo assim, possibilidades de ações extensionistas úteis e que realmente sejam de interesse social. Segundo Ziman (1994), a problematização ajuda no desenvolvimento crítico dos educandos, contribuindo para a plena formação do cidadão.

Assim como nas DCN da Física, mas de uma forma mais clara, as DCN para química fazem uma alusão à necessidade da não compartimentalização dos conteúdos e à busca pela interdisciplinaridade entre Química e outras áreas que estão relacionadas com os temas propostos aos alunos.

\section{Conteúdos Curriculares}

Os cursos de Física são orientados a constituir dois núcleos: o comum e os módulos sequenciais. O comum é responsável pelas disciplinas de conteúdo específico, comporta aproximadamente metade da carga horária do curso, conforme orientação deste documento. Este núcleo aborda conteúdos de Física Geral, Matemática, Física Clássica, Física Moderna e Contemporânea, bem como as disciplinas complementares como tópicos de Química, Biologia, Ética, Filosofia e História da Ciência, etc.

Por outro lado, os módulos têm suas disciplinas dispostas conforme a modalidade de cada curso. Analisamos aqui as oferecidas para a licenciatura, ou seja, para o físico educador. Nesta modalidade, a prioridade são as disciplinas relacionadas ao Ensino da Física, atendendo vários itens como instrumentalização de professores, produção de materiais instrucionais e, no caso de cursos com modalidade interdisciplinar, este módulo também trata das relações entre outras áreas, com disciplinas específicas para o tipo de curso. Por exemplo, Licenciatura em Física e Química ou Licenciatura em Física e Biologia.

Para os cursos de Ciências Biológicas, nos conteúdos básicos, encontramos além de Biologia Celular, Evolução, Ecologia e conhecimentos relacionados à Matemática, à Física e a Química, os chamados Fundamentos Filosóficos e Sociais. Estes orientam uma reflexão ética relacionada ao exercício profissional, considerando a História, a Sociologia e a Antropologia da ciência.

Esta visão apresentada nas DCN dos cursos de Ciências Biológicas está em sintonia com a perspectiva de Ziman (1994). Este autor argumenta em seu trabalho a importância de reconhecer a ciência e a tecnologia como instituições sociais, repletas de aspectos políticos, sociológicos e econômicos. Todos estes fatores devem estar, segundo este autor agregados aos estudos dos conteúdos básicos, caracterizando de certa forma, o enfoque sociológico da ciência.

Nos conteúdos específicos para a licenciatura, destacamos, um cuidado em contemplar uma visão geral dos processos formativos dos educandos, observando tanto os currículos quanto as estratégias de trabalho. Segundo Cachapuz, Praia e Jorge (2004), 
devemos considerar questões pertinentes sobre o "para que" e "como" os currículos devem ser feitos e seguidos e as estratégias devem ser elaboradas e executadas. Esta condição torna-se indispensável se considerarmos a plena formação orientada nas diretrizes.

A mesma divisão pode ser vista nos cursos de Química. Nestes, as DCN orientam para a separação entre conteúdos básicos e específicos. Os primeiros, contemplam conteúdos de Matemática, Física e Química, enquanto os segundos buscam especificações regionais que priorizem aquisições de habilidades mais necessárias e adequadas para a realidade do contexto (Parecer CNE/CES no 1.303, 2001).

Em relação a este item, nas três DCN, um apontamento claro de atenção aos conteúdos específicos, deixando evidente o que precisa ser estudado, sem destacar como e para que serve tal intento.

Frente a esta situação, Aikenhead (1994) defende que devemos trabalhar com o ensino de Ciências partindo de situações e fenômenos naturais que estão de uma forma ou outra, embutidos no ambiente social e tecnológico dos estudantes. Esta perspectiva constitui uma das diferentes formas de contextualização e caracteriza-se por ser um dos enfoques da abordagem CTS. Reforçando esta visão, Santos afirma que:

Não se trata de simplificar currículos, reduzindo conteúdos, mas sim de ressignificá-los socialmente, de forma que possam ser agentes de transformação social em um processo de educação problematizadora que resgate o papel da formação da cidadania (Santos, 2007, p. 10).

Ainda referente ao exposto, Cachapuz, Praia e Jorge (2004) alertam para o denominado "estatuto epistemológico" da Educação em Ciências, que precisa ser considerado no processo de ensino. Para que isso ocorra, faz-se necessário a justificação social do ensino, que implica em considerar novas formas de currículo e de estratégias de trabalho.

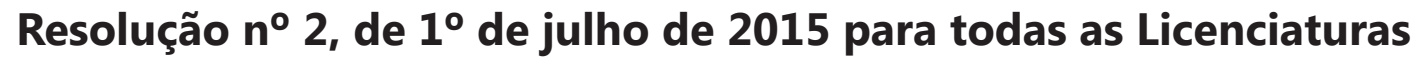

Em 2015, o Governo Federal, através do Ministério da Educação e do Conselho Nacional de Educação, publica uma nova resolução para nível superior nas licenciaturas e na formação pedagógica.

Este documento está dividido em capítulos conforme o sumário abaixo:

Capítulo I - Das Disposições Gerais;

Capítulo II - Da Formação dos Profissionais do Magistério para Educação Básica: Base Comum Nacional;

Capítulo III - Do(a) Egresso(a) da Formação Inicial e Continuada;

Capítulo IV - Da Formação Inicial do Magistério da Educação Básica em Nível Superior;

Capítulo V - Da Formação Inicial do Magistério da Educação Básica em Nível Superior: Estrutura e Currículo;

Capítulo VI - Da Formação Continuada dos Profissionais do Magistério; 
Capítulo VII - Dos Profissionais do Magistério e sua Valorização;

Capítulo VIII - Das Disposições Transitórias.

A resolução começa considerando que é necessária a construção de um ensino com uma sólida formação teórica e prática com abordagens interdisciplinares, valorizando o compromisso social da educação. Também recomenda, entre outros apontamentos, a caracterização do currículo, considerando que este deve ser:

[...] o conjunto de valores propício à produção e à socialização de significados no espaço social e que contribui para a construção da identidade sociocultural do educando, dos direitos e deveres do cidadão, do respeito ao bem comum e à democracia, às práticas educativas formais e não formais e à orientação para o trabalho (Parecer CNE/CP 2 de 2015, 2015, p. 2).

Essa formação sociocultural, segundo Aikenhead (1985) ocorre quando a educação oferece a possibilidade de relação entre a atividade científica e suas implicações sociais e ambientais. Por outro lado, para Acevedo-Diaz (2001) considera que a perspectiva CTS contribui para a formação de um cidadão consciente e crítico na medida em que favorece discussões sobre influências do desenvolvimento científico e tecnológico, essenciais para a pretendida intenção da resolução com o compromisso social da Educação.

Ainda é possível identificar, já nas primeiras linhas do documento, um apelo acerca da interdisciplinaridade. Nesta linha, Ziman (1994) defende que uma das maiores mudanças que o ensino de Ciências tem promovido nos últimos anos é a tentativa de se fazer um estudo de forma interdisciplinar, fornecendo uma formação integral e contextualizada dos fenômenos. Para este autor, quando utilizamos a abordagem CTS, estamos necessariamente abordando temas de cunho social, pertinentes a um leque de disciplinas que se relacionam pelo contexto e pelos fenômenos envolvidos.

\section{Das Disposições Gerais}

Neste capítulo, as orientações estão direcionadas para a complexidade do processo pedagógico como sendo algo intencional e metódico, envolvendo conhecimentos específicos, de forma interdisciplinar e buscando a construção de valores éticos inerentes à socialização de diferentes visões de mundo (Parecer CNE/CP 2 de 2015, 2015).

Além disso, merece destaque nesta análise, o parágrafo que trata dos princípios da formação dos profissionais da educação básica, considerando que este recomenda a promoção das condições de emancipação dos indivíduos, contribuindo para diminuir as desigualdades sociais.

As possibilidades para estas condições, segundo Santos e Mortimer (2002), são oferecidas quando construímos um ensino que vai além da cientificização da técnica. Esta, segundo os autores, foi provocada pelo desenvolvimento do modo de produção capitalista e faz da escola um instrumento a serviço do cientificismo, criando uma relação ideológica de domínio na relação entre o sistema e os aprendizes. 


\section{Da Formação dos Profissionais do Magistério para Educação Básica: Base Comum Nacional}

Neste capítulo, fica muito claro o apelo para que os profissionais do magistério procurem conduzir o egresso à possibilidade de integração entre conhecimentos e o exercício da cidadania, acompanhando mudanças educacionais e sociais que acontecem junto às transformações epistemológicas do conhecimento. Conforme a Resolução, é preciso conduzir o egresso:

[...] à integração e interdisciplinaridade curricular, dando significado e relevância aos conhecimentos e vivência da realidade social e cultural, consoantes às exigências da educação básica e da educação superior para o exercício da cidadania e qualificação para o trabalho (Parecer CNE/CP 2 de 2015, 2015, p. 6).

Segundo Bazzo (2010), para que este elo entre conhecimento e exercício da cidadania exista, é preciso que os educandos sejam conscientizados das mudanças provocadas pelo progresso da ciência e da tecnologia, mas principalmente, faz-se necessário que todos os envolvidos no processo estejam cientes das mudanças de cunho educacional, social e ético que tais eventos provocam, bem como a importância da participação na tomada de decisões junto a tais eventos.

Ainda, em relação à formação dos profissionais, a resolução orienta para a "promoção de espaços para a reflexão crítica", com a "intenção de possibilitar o desenvolvimento da criticidade e da criatividade" (Parecer CNE/CP 2 de 2015, 2015, p. 6).

Esta formação crítica dos educandos é defendida por Aikenhead (2002). Segundo este autor, o desenvolvimento da criticidade ajuda a derrubar a concepção da ciência livre de valores, autoritária e impessoal. Na óptica de Aikenhead, a ciência deve ser vista por professores e, consequentemente, proposta para os educandos, como um pensamento articulado com as percepções humanísticas e sociais, superando assim a visão de que a escola está apenas procurando formar um cientista.

\section{Do(a) Egresso(a) da Formação Inicial e Continuada}

Destacamos aqui a clara orientação para os princípios do enfoque CTS, indicando que o egresso:

[...] deverápossuir um repertório de informaçõese habilidades composto pela pluralidade de conhecimentos teóricos e práticos, resultado do projeto pedagógico e do percurso formativo vivenciado cuja consolidação virá do seu exercício profissional, fundamentado em princípios de interdisciplinaridade, contextualização, democratização, pertinência e relevância social, ética e sensibilidade afetiva e estética (Parecer CNE/CP 2 de 2015, 2015, p. 7).

Para o desenvolvimento destes princípios, Auler e Delizoicov (2001) sugerem que aproximações com o referencial freiriano são úteis, pois a perspectiva problematizadora e dialógica de Freire pode ajudar licenciandos e licenciados a buscar esse repertório de habilidades capazes de desenvolver as competências pretendidas nos educandos da 
escola básica.

Outro destaque neste capítulo que está relacionada com o enfoque CTS, refere-se à relação entre escola e a sociedade, orientando que os cursos de Licenciatura onde os educandos estão inseridos devem:

[...] promover diálogo entre a comunidade junto a quem atuam e os outros grupos sociais sobre conhecimentos, valores, modos de vida, orientações filosóficas, políticas e religiosas próprios da cultura local (Parecer CNE/CP 2 de 2015, 2015, p. 8).

Nos estudos sobre as perspectivas educacionais com a abordagem CTS, Linsingen afirma que:

[...] ao nos referimos à educação CTS, estaremos apontando para questões que envolvem os variados aspectos das relações sociais e econômicas regionais, abarcando o campo das políticas públicas de C\&T com suas percepções de relevância. Ou seja, interessa reestabelecer o elo entre ciência e sociedade no ensino de ciências e tecnologia na América Latina por meio da explicitação de sua natureza social, cultural, política e econômica (Linsingen, 2007, p.2).

\section{Da Formação Inicial do Magistério da Educação Básica em Nível Superior}

As orientações sugerem que as diversidades sejam respeitadas, mas que mesmo assim, constituam-se núcleos de estudo de formação geral, de forma interdisciplinar, abordando uma diversidade de temas, entre eles cidadania, educação ambiental e estudo referente às demandas sociais. A resolução sugere ainda uma "articulação com o contexto educacional, em suas dimensões sociais, culturais, econômicas e tecnológicas” (Parecer CNE/CP 2 de 2015, 2015, p. 9), caracterizando assim, um dos maiores desafios para a prática destas orientações, pois segundo estas diretrizes, são necessários os conteúdos de formação geral para a formação do acadêmico, assim como é imprescindível a "aplicação ao campo da educação de contribuições e conhecimentos, como o pedagógico, o filosófico, o histórico, o antropológico, o ambiental-ecológico, o psicológico, o linguístico, o sociológico, o político, o econômico, o cultural (Parecer CNE/CP 2 de 2015, 2015, p.10). Para Aikenhead (1994) e Ziman (1994), os currículos devem ser elaborados pensandose nos alunos e, para facilitar esta relação, o uso da interdisciplinaridade pode construir ligações necessárias para a contextualização, possibilitando assim, de forma simultânea, a abordagem de conhecimentos científicos, as relações CTS.

\section{Da Formação Inicial do Magistério da Educação Básica em Nível Superior: Estrutura e Currículo}

Neste capítulo, o documento orienta para que os cursos tenham um número mínimo de horas destinadas às diversas linhas de formação para o acadêmico, desde as horas para estudos de conteúdos específicos das áreas, até as que contemplam os núcleos citados no capítulo anterior. Observamos aqui a recomendação para que os cursos de licenciatura, além de oferecer os "conteúdos específicos da respectiva área 
de conhecimento" (Parecer CNE/CP 2 de 2015, 2015, p. 11), também dediquem uma considerável carga horária para o desenvolvimento de fundamentos sobre Educação, considerando metodologias e atividades de extensão.

\section{Da Formação Continuada dos Profissionais do Magistério}

Uma das orientações para a formação continuada dos profissionais do magistério consiste em acompanhar a inovação e o desenvolvimento associados à ciência e à tecnologia.

Auler e Delizoicov (2001) discorrem sobre alguns cuidados que devemos ter com o determinismo tecnológico. Segundo os autores, é necessário, em primeiro lugar, destacar que a ciência, a tecnologia e os avanços provocados por elas são uma atividade social e a direção tomada por estes avanços são, ou deveriam ser, impressos pela sociedade.

Assim como nesta resolução, Tardif (2002), também orienta para a necessidade da formação continuada dos profissionais do magistério. Segundo este teórico, as atividades de extensão citadas no capítulo anterior e os cursos de formação podem contribuir para uma mudança na postura epistemológica dos atores da educação quando proporcionam momentos de discussões acerca da ação docente, seguidos de oportunidades de experiências práticas, preferencialmente ainda durante a vida acadêmica.

\section{Análise das Relações}

As DCN para as licenciaturas constituem a orientação oficial para a elaboração dos PPC dos cursos. Logo, acreditamos que as graduações são influenciadas por estes documentos oficiais.

Ao analisarmos as diretrizes procuramos, conforme nosso objetivo, relações com o enfoque CTS, a fim de identificarmos como os futuros professores podem desenvolver seus conhecimentos e também como podem aprender a trabalhar com o ensino das Ciências.

Percebemos, após o estudo realizado nestas diretrizes, que existe uma considerável relação entre as orientações destes documentos e os princípios do enfoque CTS. Identificamos, conforme os itens que pontuamos nas análises, que a intensidade deste vínculo varia dependendo das diretrizes do curso que estudamos.

Para as DCN dos cursos de Física, encontramos um elo muito tênue e superficial com a abordagem CTS. Este elo pode ser observado, por exemplo, em apontamentos que orientam para a busca de "novas formas de saber e de fazer científico e tecnológico", valorizando "diferentes contextos sócio-políticos, culturais e econômicos", reconhecendo "as relações do desenvolvimento da Física com outras áreas do saber, tecnologias e instâncias sociais, especialmente contemporâneas", através do uso de conteúdos "especializados e interdisciplinares". Ou seja, a inclusão de itens como a valorização dos contextos sociais e culturais, promoção de uma Física que valorize questões contemporâneas e o uso da interdisciplinaridade, são evidências que remetem 
à abordagem estudada.

Para as Ciências Biológicas, as diretrizes orientam para um ensino mais crítico e social, aumentando assim a intensidade da relação procurada nesta pesquisa. Identificamos esta conexão, já no início do documento, diante de orientações para uma "formação multi e interdisciplinar", visando um profissional com postura ética e cidadã, "pautada por critérios humanísticos". Além de pontuar literalmente a necessidade de relacionarmos a ciência com a tecnologia e com a sociedade, neste documento existe uma preocupação com o processo histórico da produção do conhecimento e com o fator social e antropológico da ciência, itens considerados fundamentais para o enfoque CTS.

Ao analisarmos as DCN para os cursos de Química, também encontramos uma considerável relação com a abordagem CTS. Reconhecemos este elo quando o documento orienta para um ensino que atenda seu "papel social", abordando conteúdos que não fiquem "seccionados" nem "departamentalizados", compreendendo "criticamente os aspectos sociais, tecnológicos, ambientais, políticos e éticos relacionados às aplicações da Química na sociedade". Nestas diretrizes, ainda se evidencia recomendações quanto ao cuidado com as "especificações regionais" e a "realidade do contexto".

Quanto à orientação de 2015, percebe-se a construção de um reforço em itens como "construção de valores éticos" em um ensino "interdisciplinar, contextualizado e com relevância social", sugerindo, por fim, que os acadêmicos tenham condições de acompanhar as inovações tecnológicas e científicas.

Assim, esta pesquisa mostrou que alguns aspectos coexistem nas Diretrizes Curriculares Nacionais para os cursos analisados, na Orientação de 2015 e no enfoque CTS. Por um lado, fica evidente a preocupação expressa no documento referente ao desenvolvimento de um ensino contextualizado, não fragmentado, capaz de despertar no acadêmico uma personalidade crítica e cidadã. Todos estes adjetivos caracterizam também a abordagem CTS.

\section{Considerações Finais}

A partir dos resultados deste estudo consideramos que, de fato, existem ações governamentais buscando um caminho para a melhoria do ensino das Ciências, tanto na educação básica quanto nos cursos de graduação. Tais ações resultaram nos documentos aqui analisados, restando ainda a dúvida, que não está no escopo deste trabalho, em relação a o quanto estas orientações são seguidas nos cursos acadêmicos.

Fica evidenciado, após este estudo, que as DCN para as licenciaturas, valorizam o desenvolvimento de um ensino contextualizado, interdisciplinar e com olhos para o despertar crítico, ético e integral dos acadêmicos. Estas características mencionadas também compõe o corpo do enfoque CTS, conforme os referenciais teóricos que nos serviram de alicerce durante a pesquisa.

Também consideramos que, com este trabalho, estamos possibilitando para os envolvidos, tanto da educação superior quanto da educação básica, aporte para análises e discussões sobre o uso de novas abordagens no ensino das Ciências, nas quais a 
contextualização e a interdisciplinaridade nos parecem realidades imprescindíveis para a organização das práticas educacionais.

No trilho de nosso objetivo, percebemos a confluência entre os documentos oficiais, aqui analisados e o enfoque CTS e, considerando nosso referencial teórico, reafirmamos a importância deste estudo, por abordar características de um enfoque que está totalmente voltado para as prerrogativas que buscamos para a melhoria do ensino das Ciências.

Acreditamos que a concretização de um ensino de Ciências com as características discutidas só será uma realidade em todos os níveis escolares se os futuros professores vivenciarem estas discussões. Segundo Nóvoa, a formação plena do educador deve acontecer na articulação entre a Universidade e a Escola, valorizando não só conteúdos, mas o papel da profissão de educador e sua plena competência profissional (Nóvoa, 1995).

Por fim, entendemos que, independente do que os documentos oficiais exigem, as Universidades precisam formar um educador motivador, que não tenha medo de inovar e esteja ciente de sua importância como mediador e incentivador do despertar crítico, ético e cidadão das futuras gerações.

\section{Referências}

Acevedo-Díaz, J. (2001). Cambiando la prática docente en la enseñanza de las ciências a través de CTS. En Sala de lectura CTS+I da OEI.

Aikenhead, G. S. (1985). Collective decision making in the social context of science. Science Education, 69(4), 453-475.

Aikenhead, G. S. (1994). What is STS science teaching? In J., Solomon, \& G. Aikenhead. STS education: international perspectives on reform. New York: Teachers College Press. Aikenhead, G. S. (2003). STS Education: a rose by any other name. In A Vision for Science Education: Responding to the world of Peter J. Fensham, (ed.) Cross, R.: Routledge Press. Auler, D. (2002). Interações entre Ciência-Tecnologia-Sociedade no Contexto da Formação de Professores de Ciências; Tese de Doutorado; UFSC, Florianópolis SC.

Auler, D., \& Bazzo W. A. (2001). Reflexões para a implementação do Movimento CTS no contexto educacional Brasileiro, Ciência \& Educação, 7(1), 1-13.

Auler, D., \& Delizoicov, D. (2001). Alfabetização Científico-Tecnológica Para Quê?; Ensaio - Pesquisa em Educação em Ciências, 3(1), 122-134.

Bazzo, W. A. (2010) Ciência, tecnologia e sociedade e o contexto da educação tecnológica; 2. ed. Florianópolis: UFSC.

Cachapuz, A., Praia, J., \& Jorge, M. (2004). Da Educação em Ciência às Orientações para o Ensino das Ciências: Um Repensar Epistemológico. Ciência \& Educação, 10(3), 363-381. 
Cachapuz, A., Paixão, F., Lopes, J. B., \& Guerra, C. (2008). Do Estado da Arte da Pesquisa em Educação em Ciências: Linhas de Pesquisa e o Caso "Ciência-Tecnologia-Sociedade". Alexandria Revista de Educação em Ciência e Tecnologia, 1(1), 27-49.

Cerezo, J. A. L. (2002). Ciencia, Tecnología y Sociedad: El estado de la cuestión en Europa y Estados Unidos. Revista Iberoamericana de Educación. 18.

Fonseca, J. J. S. (2002). Metodologia da pesquisa científica. Fortaleza: UEC.

Gerhardt ,T. E., \& Silveira D. T. (2009). Métodos de pesquisa. Universidade Aberta do Brasil - UAB/UFRGS e pelo Curso de Graduação Tecnológica - Planejamento e Gestão para o Desenvolvimento Rural da SEAD/UFRGS. Porto Alegre: Editora da UFRGS.

Linsingen, I. V. (2002). Engenharia, Tecnologia e Sociedade: Novas perspectivas para uma formação. Tese. Centro de Ciências da Educação, Universidade Federal de Santa Catarina, Florianópolis.

Linsingen, I. V. (2007). Perspectiva educacional CTS: aspectos de um campo em consolidação na América Latina. Ciência \& Ensino, 1(número especial).

Miranda, E. M. (2013). Tendências das Perspectivas Ciência, Tecnologia e Sociedade (CTS) nas Áreas de Educação e Ensino de Ciências: Uma análise a partir de teses e dissertações brasileiras e portuguesas. (Tese do Doutorado) Universidade de São Carlos - UFSCar.

Nóvoa, A. (1995). O Passado e o Presente dos Professores. In Profissão Professor. Porto: Porto Editora.

Parecer CNE/CES no 1.304. (2001). Diretrizes Nacionais Curriculares para os Cursos de Física - 2001. Recuperado de: http://portal.mec.gov.br/cne/arquivos/pdf/CES1304.pdf

Parecer CNE/CES no 1.303. (2001). Diretrizes Nacionais Curriculares para os Cursos de Química - 2001. Recuperado de: http://portal.mec.gov.br/cne/arquivos/pdf/CES1303. pdf

Parecer CNE/CES no 1.301. (2001). Diretrizes Nacionais Curriculares para os Cursos de Ciências Biológicas - 2001. Recuperado de: http://portal.mec.gov.br/cne/arquivos/pdf/ CES1301.pdf

Parecer CNE/CP 2 de 2015. (2015). Diretrizes Curriculares Nacionais para a Formação Inicial e Continuada dos Profissionais do Magistério da Educação Básica. Ministério da Educação. Aprovado em: 9/6/2015. Recuperado de http://portal.mec.gov.br/index. php?option=com_docman\&view=download\&alias=70431-res-cne-cp-002-03072015pdf\&category_slug=agosto-2017-pdf\&Itemid=30192.

Parecer CNE/CEB no 7/2010. (2013). Diretrizes Curriculares Nacionais Gerais da Educação Básica; Ministério da Educação. Secretaria de Educação Básica. Diretoria de Currículos e Educação Integral. Brasília: MEC, SEB, DICEI. Recuperado de: http:// portal.mec.gov.br/docman/julho-2013-pdf/13677-diretrizes-educacao-basica-2013pdf/file 
Pinheiro, N. A. M. (2005). Educação Crítico-Reflexiva para um Ensino Médio Científicotecnológico: A Contribuição do Enfoque CTSpara o Ensino-aprendizagem do Conhecimento Matemático. (Tese de Doutorado), UFSC, Florianópolis.

Ramos, F. P., Neves, M. C. D., \& Corazza, M. J. (2011). A ciência moderna e as concepções contemporâneas em discursos de professores-pesquisadores: entre rupturas e a continuidade. Revista Electrónica de Enseñanza de las Ciências. 10(1), 84-108.

Rosa C. W. da, \& Rosa, A. (2012). O ensino de ciências (Física) no Brasil: da história às novas orientações educacionais. Revista Iberoamericana de Educación Organización de Estados Iberoamericanos para la Educación, la Ciencia y la Cultura.

Salomon, J. J., Sagasti, F., \& Sachs-Jeantet, C. (1993, janeiro/abril). Dossiê Tecnologia, Trabalho e Desenvolvimento - Da tradição à modernidade. Estudos Avançados 7(17). São Paulo.

Santos, W. L. P. (2007). Contextualização no Ensino de Ciências por meio de temas CTS em uma perspectiva crítica. Ciência e Ensino. 1(número especial).

Santos, W. L. P. dos, \& Mortimer, E. F. (2002). Uma análise de pressupostos teóricos da abordagem C-T-S (Ciência - Tecnologia - Sociedade) no contexto da educação brasileira. Ensaio: Pesquisa em Educação em Ciências, Belo Horizonte, 2(2), 110-132.

Strieder, R. B. (2012). Abordagens CTS na educação Científica no Brasil. (Tese de Doutorado), Universidade de São Paulo, São Paulo.

Tardif, M. (2002). Saberes docentes e formação profissional. Petrópolis, R.J.: Vozes.

Tokarnia, M. (2016). Pisa: Desempenho do Brasil piora em leitura e 'empaca' em ciências, São Paulo, 2013. Recuperado de http://educacao.uol.com.br/noticias/2013/12/03/pisadesempenho-do-brasil-pioraem-leitura-e-empaca-em-ciencias.htm, acesso em maio de 2016.

Vaccarezza, L. S. (1998). Ciência, Tecnología y Sociedad: el estado de la cuestión en América Latina. Revista Iberoamericana de Educación, 18, 1-22.

Ziman, J. (1980). Teaching and learning about science and society. Cambridge: Cambridge University Press.

Ziman, J. (1994) The rationale of STS education is in the approach. In J., Solomon, \& G. Aikenhead. STS education: international perspectives on reform. New York: Teachers College Press. 


\section{Jucelino Cortez}

${ }^{(0)}$ https://orcid.org/0000-0001-8642-5605 Universidade Federal do Rio Grande do Sul Programa de Pós-Graduação em Educação em Ciência: Química da vida e saúde da UFRGS Porto Alegre, Brasil jucelinocortez@gmail.com

\section{José Claudio Del Pino}

${ }^{\circledR}$ https://orcid.org/0000-0002-8321-9774 Universidade Federal do Rio Grande do Sul Programa de Pós-Graduação em Educação em Ciência: Química da vida e saúde da UFRGS Porto Alegre, Brasil delpinojc@yahoo.com.br

Submetido em 07 de Janeiro de 2017

Aceito em 21 de Outubro de 2017

Publicado em 08 de Março de 2018 